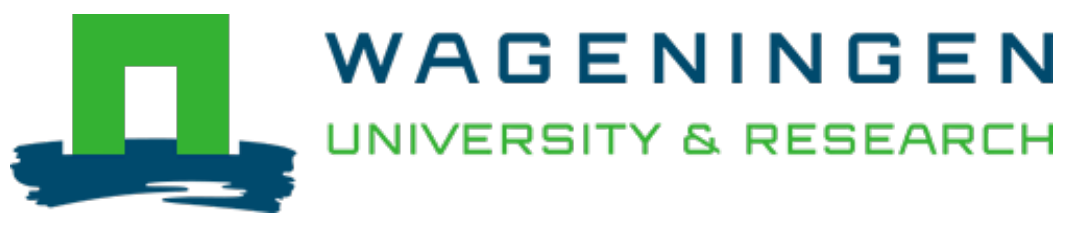

\title{
Attractiveness of sown wildflower strips to flower-visiting insects depends on seed mixture and establishment success
}

\author{
Basic and Applied Ecology \\ Scheper, Jeroen; Bukovinszky, Tibor; Huigens, Martinus E.; Kleijn, David \\ https://doi.org/10.1016/j.baae.2021.08.014
}

This article is made publicly available in the institutional repository of Wageningen University and Research, under the terms of article $25 \mathrm{fa}$ of the Dutch Copyright Act, also known as the Amendment Taverne. This has been done with explicit consent by the author.

Article 25 fa states that the author of a short scientific work funded either wholly or partially by Dutch public funds is entitled to make that work publicly available for no consideration following a reasonable period of time after the work was first published, provided that clear reference is made to the source of the first publication of the work.

This publication is distributed under The Association of Universities in the Netherlands (VSNU) 'Article $25 \mathrm{fa}$ implementation' project. In this project research outputs of researchers employed by Dutch Universities that comply with the legal requirements of Article $25 \mathrm{fa}$ of the Dutch Copyright Act are distributed online and free of cost or other barriers in institutional repositories. Research outputs are distributed six months after their first online publication in the original published version and with proper attribution to the source of the original publication.

You are permitted to download and use the publication for personal purposes. All rights remain with the author(s) and / or copyright owner(s) of this work. Any use of the publication or parts of it other than authorised under article $25 \mathrm{fa}$ of the Dutch Copyright act is prohibited. Wageningen University \& Research and the author(s) of this publication shall not be held responsible or liable for any damages resulting from your (re)use of this publication.

For questions regarding the public availability of this article please contact openscience.library@,wur.nl 


\title{
Basic and

\section{Attractiveness of sown wildflower strips to flower-visiting insects depends on seed mixture and establishment success}

\author{
Jeroen Scheper $^{\mathrm{a}, \mathrm{b}, *}$, Tibor Bukovinszky ${ }^{\mathrm{b}, \mathrm{c}}$, Martinus E. Huigens ${ }^{\mathrm{d}, \mathrm{e}}$, David Kleijn ${ }^{\mathrm{a}, \mathrm{b}}$ \\ ${ }^{a}$ Plant Ecology and Nature Conservation Group, Wageningen University, P.O. Box 47, Wageningen 6700 AA, \\ Netherlands \\ ${ }^{\mathrm{b}}$ Resource Ecology Group, Wageningen University, P.O. Box 47, Wageningen 6700 AA, Netherlands \\ ${ }^{\mathrm{c}}$ National Reference Centre of plant health, Dutch National Plant Protection Organization, Wageningen, Netherlands \\ ${ }^{\mathrm{d}}$ De Vlinderstichting (Dutch Butterfly Conservation), P.O. Box 506, Wageningen 6700 AM, Netherlands \\ ${ }^{\mathrm{e}}$ Education \& Student Affairs, Wageningen University, P.O. Box 59, Wageningen 6700 AB, Netherlands
}

Received 24 December 2020; accepted 29 August 2021

Available online 31 August 2021

\begin{abstract}
Establishing wildflower strips has been suggested as an effective measure to promote pollination services, pest control or general insect biodiversity, but little is known about the integration of these different objectives when selecting flower seed mixtures. In ten agricultural landscapes in the Netherlands, we established a wildflower strip $(0.4-4.9$ ha) with half of each strip sown with a mixture targeting longer-tongued pollinators and the other half sown with a mixture targeting shorter-tongued pollinators and natural enemies. We determined establishment success of sown wildflowers and evaluated the attractiveness of the established flower communities to multiple functional groups of flower visitors: bumblebees (long-tongued pollinators), hoverflies (short-tongued pollinators and natural enemies), and butterflies and total flower-visitor richness (indicators of wider biodiversity values). Bumblebees clearly preferred the pollinator-targeted seed mixture and were positively associated with cover of Fabaceae and negatively with Apiaceae. Hoverflies consistently preferred the natural enemy mixture and were positively associated with Apiaceae. The other target groups displayed no clear responses to seed mixture type but instead were associated with local flower richness within strips. Across sites, responses of flower-visitors to sown mixture types did not depend on wildflower strip size, proportion of surrounding semi-natural habitat, or flower variables. However, all flower-visitors except butterflies increased with increasing established cover or richness of (sown) flower species across sites. Our results suggest that, although species-rich wildflower strips may benefit several species groups, maximising different objectives involves trade-offs between functional groups that prefer short- or long-corolla flowers. Furthermore, our study suggests that sowing a wildflower mixture does not necessarily result in a vegetation with the same composition as the seed mixture as species may establish poorly or not at all. Selection of flower species for seed mixtures should therefore, in addition to insect target group, take the establishment characteristics of plant species into account.
\end{abstract}

○ 2021 Gesellschaft für Ökologie. Published by Elsevier GmbH. All rights reserved.

Keywords: Flower plantings; Pollination; Pest control; Agri-environmental measures; Bumblebees; Hoverflies; Butterflies

\footnotetext{
*Corresponding author.

E-mail address: jeroen.scheper@wur.nl (J. Scheper).
} 


\section{Introduction}

Agricultural intensification and land use change have, mainly through associated reductions in the availability of floral resources in agricultural landscapes (Scheper et al., 2014), caused sharp declines in many flower-visiting insect species (Bartomeus, Stavert, Ward \& Aguado, 2019; Powney et al., 2019; Van Strien, van Swaay, van Strien-van Liempt, Poot \& WallisDeVries, 2019). In addition to concern about the loss of biodiversity per se, this has raised concern about potential consequences for the delivery of ecosystem services by flower-visiting insects. Insects that depend on flowers for pollen and nectar play an essential role in the pollination of wild plants and crops (Ollerton, Winfree \& Tarrant, 2011; Rader et al., 2016) and many flower-visiting insect species, such as aphidophagous hoverflies and (parasitoid) wasps, provide natural pest control services in agricultural landscapes (ChaplinKramer, de Valpine, Mills \& Kremen, 2013; Schmidt et al., 2003).

Since the early 1990s, agri-environmental measures that aim to enhance floral resources, such as sowing wildflower seed mixtures in field margins or set-aside fields (henceforth referred to as wildflower strips), have increasingly been implemented in many European countries to mitigate the decline of flower-visiting insects (Haaland, Naisbit \& Bersier, 2011). Initially the main objective of these wildflower strips was to promote biodiversity in general (Aviron et al., 2006; Feber, Smith \& Macdonald, 1996; Thomas \& Marshall, 1999). However, with a steadily increasing demand for agricultural products, measures are needed that help increase agricultural production without negatively impacting biodiversity (Bommarco, Kleijn \& Potts, 2013). Consequently, there is a growing interest in establishing wildflower strips that specifically enhance the insect species groups that provide pollination and biological pest control services (Albrecht et al., 2020; Cresswell, Cunningham, Wilcox \& Randall, 2019).

With land being scarce, the establishment of wildflower strips should ideally address biodiversity conservation, crop pollination and natural pest control at the same time. However, these different conservation objectives are thought to require different flower seed mixtures, because foraging traits and food preferences differ between different functional groups of flower visitors. Wildflower strips specifically targeted at pollinating insects are often composed of flower species with long corollas such as Fabaceae to benefit bumblebees (Pywell et al., 2006; Wood, Holland, Hughes \& Goulson, 2015), the main group of wild crop pollinators in Europe (Kleijn et al., 2015). In contrast, flower mixtures targeting the main natural enemies of agricultural pests (e.g. predatory hoverflies, and parasitoid and predatory wasps) are generally dominated by short-corolla flower species such as Apiaceae and Asteraceae (Campbell, Biesmeijer, Varma \& Wäckers, 2012; Tschumi et al., 2016; Tschumi, Albrecht, Entling \& Jacot, 2015; Van Rijn \& Wäckers, 2016).
However, the benefits of these pollination and bio-control mixtures for wider biodiversity of flower-visiting insects may be limited (Wood, Holland \& Goulson, 2015, 2017).

Determining how plant species composition affects the use of mixtures by different functional groups of flower visitors as well as wider biodiversity values can help explore whether it is possible to have multi-functional flower strips and what plant species these should contain. Although this has been the focus of a number of recent studies (Balzan, Bocci \& Moonen, 2014; Campbell et al., 2012; Korpela, Hyvönen, Lindgren \& Kuussaari, 2013; Warzecha, Diekötter, Wolters \& Jauker, 2018), these have been restricted to plot-scale comparisons of the attractiveness of different sown flower seed mixtures to different flower visitor groups. Such studies provide valuable information, but their results are difficult to scale up to implications for field- or farm-scale management. In real-world agricultural practice, established wildflower strips are generally several orders of magnitude larger than those examined in plot-scale studies (Boetzl, Krimmer, Krauss \& SteffanDewenter, 2019; Grass et al., 2016). This may affect the attractiveness of sown wildflowers to different flower-visitor groups (Carvell et al., 2011; Nielsen et al., 2012). Furthermore, sowing a wildflower mixture does not automatically result in a vegetation with the same composition as the seed mixture (Bretzel, Pezzarossa, Benvenuti, Bravi \& Malorgio, 2009; Schmidt, Kirmer, Kiehl \& Tischew, 2020). In practice, factors such as soil type, original land use, sowing method and weather conditions strongly influence the establishment success of wildflower seed mixtures, and, in turn, flower-visitor responses. Plant species that are highly attractive to target insect groups under experimental conditions but fail to establish when sown in real-world situations have limited value. Finally, since flower-visitor responses to wildflower strips have been shown to depend on the availability of alternative floral resources in the surrounding landscape (Scheper et al., 2015), the relative attractiveness of different sown seed mixtures may depend on the surrounding landscape as well. Evaluating the attractiveness of different seed mixtures to flower-visitors should therefore be performed at spatial scales relevant to farming practice, and should take variation in local and landscape environmental conditions into account. However, to date such evaluations are lacking.

In this study we performed a landscape-scale experiment to evaluate the attractiveness of two functionally contrasting flower seed mixtures to multiple functional groups of flower-visitors. In ten agricultural landscapes in the Netherlands we established wildflower strips ranging in size from 0.4 to 4.9 ha. Half of each strip was sown with a wildflower seed mixture typically targeting longer-tongued pollinators; the other half was sown with a mixture targeting shortertongued pollinators and natural enemies. We surveyed flowers and flower-visiting insects in the flower strips to 1) compare the attractiveness of the two mixtures to pollinators, natural enemies and the wider flower-visitor community, 2) assess whether and how responses of flower-visitors are 
affected by local and landscape-scale factors such as size of the flower strips, established flower cover and richness in the strips and surrounding landscape composition, and 3) examine which plant taxa are associated with each of the flower visitor groups. The insights gained from this study will help develop seed mixtures for flower strips that may simultaneously realise conservation and ecosystem service objectives.

\section{Materials and methods}

\section{Study design}

In 2012, we selected ten 50 ha study sites located in landscapes predominantly containing agricultural land in the southern part of the Netherlands (Bukovinszky et al., 2017; Kleijn et al., 2018). Eight sites were located on sandy soil; two sites were located on loamy soil. The size of the study sites was based on the average size of Dutch farms (42 ha (CBS, 2015)), thereby reflecting the relevant spatial scale at which individual farmers can implement measures to promote flower-visiting insects. The study sites covered a gradient in percentage cover of open semi-natural habitat (e.g. extensively used grasslands, fallows, field boundaries, road verges and ditch banks) $(\min =0.3 \%, \max =12.0 \%$, mean $\pm \mathrm{SE}=5.0 \pm 1.4$; see Appendix A: Table A1). Minimum distance between sites was $4 \mathrm{~km}$.

A wildflower strip was established on an agricultural field located in the centre of each study site. Wildflower strips ranged in size from 0.4 to 4.9 ha and were sown on fields that differed in original land use, which may affect the establishment of sown and spontaneously emerging plant species. Four fields, owned by farmers, were intensively managed arable fields; the other fields were extensively managed (three former low-input grasslands and three extensively managed arable fields) and owned by nature organisations or Wageningen University \& Research. The seed mixtures were provided to the land owners who were responsible for preparing the soil and sowing the mixtures. Eight wildflower strips were sown in autumn 2012; the other two wildflower strips were sown in early spring 2013. At each site, half of the wildflower strip was sown with a seed mixture that was composed to target longer-tongued pollinators (henceforth referred to as "pollinator mixture"); the other half was sown with a mixture typically targeting shorter-tongued pollinators and natural enemies ("natural enemy mixture"). The pollinator mixture predominantly consisted of long-corolla flower species (Fabaceae species contributing 35\% to the total weight of the seed mixture, no Apiaceae species included in the mixture), whereas the natural enemy mixture comprised predominantly short-corolla flower species $(40 \%$ Apiaceae, no Fabaceae) (Table 1). Both mixtures were sown at a rate of $10 \mathrm{~kg}$ seeds/ha. In autumn 2013 (late September - early October) all wildflower strips were mown, with cuttings removed, to suppress dominance of spontaneously established grasses.

\section{Surveying flowers and flower-visiting insects}

Flower-visiting insects and flowers were surveyed in 2013 and 2014, in the first and second year after establishment of the flower strips. Flower strips were surveyed three times in 2013 (June, July and August) and two times in 2014 (June and August). We focused on three distinct functional species groups: bumblebees, hoverflies and butterflies. Bumblebees are the primary group of wild crop pollinators in Europe (Kleijn et al., 2015), while (aphidophagous) hoverflies can provide both pest control and pollination services (Pekas, De Craecker, Boonen, Wäckers \& Moerkens, 2020). Butterflies are often used as indicators for conservation value (Korpela et al., 2013; Stefanescu, Peñuelas \& Filella, 2005) and are generally appreciated by the public for their aesthetic value (Rada et al., 2019). Flower-visitors were sampled using standardized five-minute transect walks in $5 \mathrm{~m} \times 10 \mathrm{~m}$ transects. In each flower strip, we randomly located five (non-overlapping) transects in the pollinator mixture and five transects in the natural enemy mixture on each sampling occasion. Flower-visiting insects were surveyed on days with dry weather, low wind speeds and temperatures above $15^{\circ} \mathrm{C}$, between 9:00 and 18:00 h. Flowervisitors that could not be identified on the wing were collected using an insect net and brought to the laboratory for later identification. In each transect, flower availability was determined by recording flower cover and species richness of all forb species flowering at the time of the survey. We calculated the total flower cover for each recorded forb species as the total number of flower units (which were e.g. single flowers for Papaveraceae, flower heads for Asteraceae, umbels for Apiaceae and racemes for Fabaceae) $\times$ the mean surface area of the flower unit, divided by the transect area (Scheper et al., 2015).

\section{Data analysis}

To examine differences in established flower cover and richness between mixtures, and whether these depended on across-site differences in wildflower strip size and original land use, we used linear mixed models and an information theoretic approach based on data pooled over the five transects per mixture, sampling round and year. These analyses were performed separately for total flower cover in the strips (i.e. including spontaneously established species), total flower richness, cover of established sown flower species, and the percentage of flower species in the seed mixtures that established. We constructed a model set consisting of models containing all combinations (i.e. including an intercept only model) of the fixed factors mixture (pollinator vs. natural enemy), original land use (intensive vs. extensive) 
Table 1. Plant species included in the different wildflower seed mixtures, and their presence and average cover per mixture (averaged over survey rounds and years) in the experimental flower strips.

\begin{tabular}{|c|c|c|c|c|}
\hline Species & Family & $\begin{array}{l}\text { Proportion in } \\
\text { seed mix }\end{array}$ & \# sites recorded & Average cover $(\%) \pm$ SE per site (range) \\
\hline \multicolumn{5}{|l|}{ Pollinator mixture } \\
\hline Borago officinalis & Boraginaceae & 0.10 & 10 & $0.029 \pm 0.024(0-0.636)$ \\
\hline Centaurea jacea & Asteraceae (Carduoideae) & 0.10 & 10 & $0.045 \pm 0.013(0-0.442)$ \\
\hline Crepis biennis & Asteraceae (Cichorioideae) & 0.05 & 7 & $0.032 \pm 0.019(0-0.522)$ \\
\hline Hypochaeris radicata & Asteraceae (Cichorioideae) & 0.10 & 10 & $0.101 \pm 0.025(0-0.707)$ \\
\hline Lotus corniculatus & Fabaceae & 0.01 & 8 & $0.002 \pm 0.001(0-0.027)$ \\
\hline Malva sylvestris & Malvaceae & 0.10 & 10 & $0.128 \pm 0.028(0-1.139)$ \\
\hline Onobrychis viciifolia & Fabaceae & 0.08 & 2 & $<0.001 \pm<0.001(0-0.001)$ \\
\hline Papaver rhoeas & Papaveraceae & 0.10 & 10 & $0.276 \pm 0.099(0-2.656)$ \\
\hline Tanacetum vulgare & Asteraceae (Asteroideae) & 0.10 & 10 & $0.007 \pm 0.005(0-0.269)$ \\
\hline Trifolium incarnatum & Fabaceae & 0.25 & 10 & $0.007 \pm 0.003(0-0.148)$ \\
\hline Trifolium pratense & Fabaceae & 0.01 & 8 & $0.007 \pm 0.003(0-0.078)$ \\
\hline \multicolumn{5}{|l|}{ Natural enemy mixture } \\
\hline Achillea millefolium & Asteraceae (Asteroideae) & 0.10 & 10 & $2.047 \pm 0.929(0-18.661)$ \\
\hline Anethum graveolens & Apiaceae & 0.10 & 6 & $0.055 \pm 0.034(0-1.715)$ \\
\hline Angelica sylvestris & Apiaceae & 0.05 & 1 & $<0.001 \pm<0.001(0-0.009)$ \\
\hline Anthriscus sylvestris & Apiaceae & 0.05 & 1 & $<0.001 \pm<0.001(0-0.024)$ \\
\hline Cichorium intybus & Asteraceae (Cichorioideae) & 0.10 & 9 & $0.128 \pm 0.098(0-4.426)$ \\
\hline Fagopyrum esculentum & Polygonaceae & 0.40 & 4 & $0.102 \pm 0.096(0-4.411)$ \\
\hline Foeniculum vulgare & Apiaceae & 0.10 & 5 & $0.046 \pm 0.033(0-1.389)$ \\
\hline Pastinaca sativa & Apiaceae & 0.10 & 4 & $0.032 \pm 0.021(0-0.828)$ \\
\hline
\end{tabular}

and flower strip size, and all their two-way interactions. Study site, with mixture nested within study site, was included as a random effect. Since we were interested in the generality of patterns across years and sampling rounds, we also included the combination of year and sampling round as a crossed random effect (but see Appendix A: Fig. A1 for differences between mixtures in individual rounds and years). All predictors were standardized (scaled and centred) to aid comparison of effect sizes and allow model-averaging of main effects in presence of interactions. Total flower cover and flower cover of sown species were ln-transformed to improve normality and homoscedasticity of residuals.

To examine whether abundance and richness of bumblebees, hoverflies and butterflies, and total flower visitor richness differed between the pollinator and the natural enemy mixture, and whether this was affected by local and landscape-scale environmental factors, we used an approach similar to the previous analysis. A set of models was constructed containing all possible combinations of mixture, flower strip size, percentage of semi-natural habitat, total flower cover and richness, and cover and richness of sown species in the mixtures. All two-way interactions with mixture were included as well. Total flower cover and cover of sown species were ln-transformed to reduce positive skew. Individual models within the model set were restricted to contain a maximum of three predictors to limit model complexity and the total number of models considered, given the sample size (Burnham, Anderson \& Huyvaert, 2011).
Analyses were performed using generalized linear mixed models, with Poisson error distribution and log-link function for butterfly richness and total flower-visitor richness, gaussian distribution and identity-link for bumblebee richness, and negative binomial distribution (with variance increasing quadratically with the mean) and log-link for the other response variables.

Finally, to get a more in-depth understanding of the response of flower-visitors to the different seed mixtures, we used generalized linear mixed models, based on the unpooled transect-level data, to examine how flower-visitor response variables in the transects were related to cover of specific sown flower species in the transects. In these analyses relationships between flower-visitor groups and flower composition were examined within the flower strips as a whole; i.e. without distinguishing between sown mixture types. As the range of species richness values at the transect level was limited for the individual flower-visitor groups, analyses were only performed for abundance data of the different flower-visitor groups and for total flower-visitor richness. All response variables were analysed using a negative binomial error distribution and log-link function, with variance increasing linearly with the mean for bumblebee and butterfly abundance, and quadratically for hoverfly abundance and total flower-visitor richness. Explanatory variables were total flower cover and richness, and cover of sown Borago officinalis, Centaurea jacea, Malva sylvestris, Papaver rhoeas, Apiaceae (Anethum graveolens, Angelica 
sylvestris, Anthriscus sylvestris, Foeniculum vulgare and Pastinaca sativa), Asteroideae (Achillea millefolium and Tanacetum vulgare), Cichorioideae (Crepis biennis, Hypochaeris radicata and Cichorium intybus) and Fabaceae (Lotus corniculatus, Onobrychis viciifolia, Trifolium incarnatum and T. pratense). Flower cover percentages were lntransformed (with minimum non-zero value added) to reduce positive skew. As the focus of this analysis was specifically on associations between flower-visitors and flower taxa within sites (rather than across sites), all explanatory variables were scaled within sites, years and rounds (Van de Pol \& Wright, 2009). Models incorporated study site and year-sampling round combination as random factors. For each response variable we constructed an all-subsets model set, with individual models restricted to contain a maximum of four predictors to limit model complexity and the total number of models.

In all analyses, we ranked models based on their Akaike Information Criterion values (corrected for small sample size, AICc) and restricted our candidate set to models with $\Delta \mathrm{AICc}<2$. We calculated full-model averaged parameter estimates $(\beta)$ for each explanatory variable in the candidate model set to account for model selection uncertainty (Symonds \& Moussalli, 2011). Variance inflation factors calculated for the predictors in the global models did not indicate multicollinearity in any of the analyses (all VIFs < 5). Analyses were performed using $\mathrm{R}$ version 4.0.2 (R Core Team, 2020).

\section{Results}

\section{Differences in flower establishment between mixtures and sites}

The degree of establishment of the sown flower species varied amongst species and sites, with flower cover of the sown species generally being low (Table 1). Achillea millefolium was present in relatively high cover in all sites. Borago officinalis, Centaurea jacea, Hypochaeris radicata, Malva sylvestris, Papaver rhoeas, Tanacetum vulgare and Trifolium incarnatum were also found in all sites but had lower average flower cover. In contrast, Angelica sylvestris, Anthriscus sylvestris and Onobrychis viciifolia were only recorded at one or two sites, at very low cover. Aggregated over years and rounds, on average $9.5 \pm 0.2$ of the 11 sown species were observed flowering in the pollinator mixture strips, whereas the average per site was only $4.0 \pm 0.3$ of the 8 sown species in the natural enemy mixture. Matricaria sp. (9 sites), Capsella bursa-pastoris (8 sites) and Leucanthemum vulgare ( 7 sites) were the most commonly encountered spontaneously established flower species.

Mixture type only affected the percentage of established sown flower species (explaining $38 \%$ of the variation, Appendix A: Table A.2), with the percentage of established species flowering on average per year and survey round being higher in the pollinator $(44 \%)$ than in the natural enemy mixture (22\%) (Fig. 1D). There was little support for mixture influencing total flower cover, total flower richness or sown flower cover. For total flower cover and cover of sown species there was some support for interacting effects of mixture and land use, but confidence intervals for these effects overlapped zero (Appendix A: Table A.2). Instead, model-averaging results indicated that flower cover and cover of sown species mostly depended on the main effect of original land use prior to sowing the wildflower strips, with higher cover on intensively farmed sites (Fig. 1A,C) than on sites managed by conservation organisations. Note, though, that the variation explained by just this predictor was low (Appendix A: Table A.2). Total flower richness differed according to original land use as well, but was lower on sites that were intensively farmed (Fig. 1B).

\section{Differences in flower-visitors between mixtures and sites}

A total of 2405 flower-visiting insects were recorded over the two years. Most observed flower-visitors were hoverflies (1385 individuals; 31 species), followed by butterflies (514 individuals; 28 species) and bumblebees (506 individuals; 7 species). The most frequently observed hoverfly species were Eristalis tenax (14\% of all hoverflies) and Sphaerophoria scripta (13\%), whereas Pieris rapae (26\%) and Polyommatus icarus (19\%) were the most abundant butterfly species and Bombus lapidarius (43\%) and B. terrestris/lucorum $(38 \%)$ the most abundant bumblebee species. Seven Red-Listed butterfly species were recorded: Argynnis aglaja (1 individual), Aricia agestis (5), Colias hyale (5), Hipparchia semele (1), Issoria lathonia (7), Lycaena tityrus (2) and Pyronia tithonus (2). None of the bumblebees and hoverflies were Red Listed.

Attractiveness of the sown flower seed mixtures differed across flower-visitor groups (Table 2; Appendix A: Table A.3). Bumblebee abundance (Fig. 2A,B) and richness (Appendix A: Fig. A.2A) were higher in the pollinator mixture, while hoverfly abundance (Fig. 2C) and richness (Appendix A: Fig. A.2B) were higher in the natural enemy mixture. In contrast, butterfly abundance and richness, and total flower-visitor richness, did not differ between mixture types (Table 2; Appendix A: Table A.3). Effects of mixture type did not depend on local or landscape factors for any of the flower-visitor groups, as indicated by the absence of interaction effects in the candidate model sets. However, local and landscape environmental factors did explain variation in flower-visitor abundance and richness across study sites. Bumblebee abundance increased with increasing local flower cover and percentage of semi-natural habitat across sites (Fig. 2A,B), and the single best model (model weight $\omega=1.00$ ) containing mixture type, flower cover and 

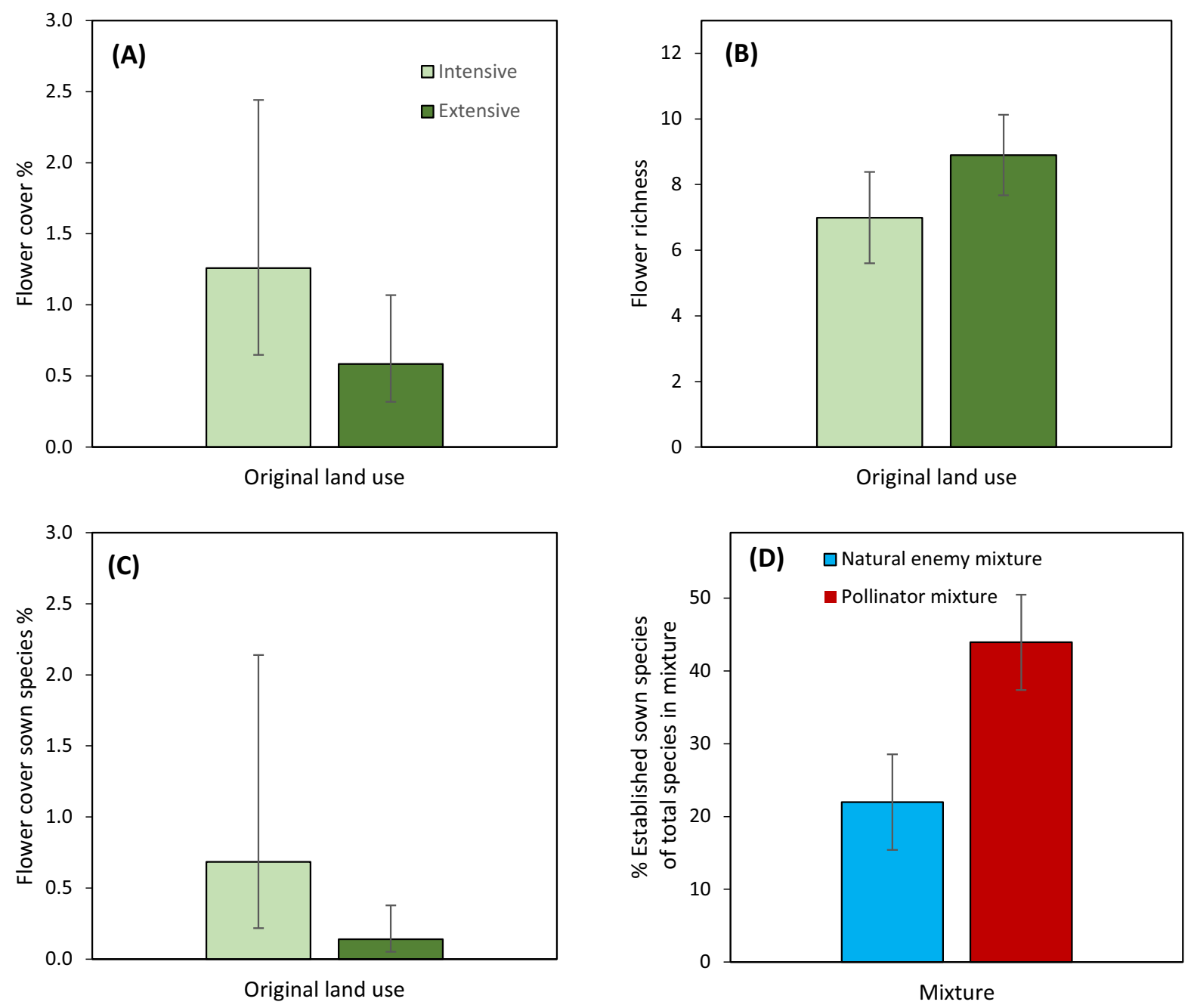

Fig. 1. (A-C) Model-estimated mean flower cover (back-transformed) (A), flower richness (B) and flower cover of sown species (back-transformed) (C) in wildflower strips sown on intensively (light green) and extensively managed agricultural fields. (D) Model-estimated mean percentage of established sown flower species of the total number of sown species in the natural enemy mixture (blue) and pollinator mixture (red) strips. Estimates represent means per $250 \mathrm{~m}^{2}$ transect area per survey round. Error bars display $95 \%$ confidence intervals.

percentage semi-natural habitat explained $48 \%$ of the variation in bumblebee abundance (Table 2). Patterns for bumblebee richness were similar (Appendix A: Fig. A.2A), but there was more model selection uncertainty associated with the effect of semi-natural habitat $(\omega=0.45$ for the highest ranked model which contained semi-natural habitat), and its 95\% CI overlapped zero (Appendix A: Table A.3). Hoverfly abundance (Fig. 2C) and richness (Appendix A: Fig. A.2B) increased with the number of established sown flower species, although the explained variation was low. Total flowervisitor richness was positively correlated with both total flower richness and the cover of established sown flower species (Fig. 2D,E), together explaining 19\% of the variation. Total flower-visitor richness tended to be positively correlated with the percentage of semi-natural habitat in the surrounding landscape as well (as indicated by the highest ranked model, $\omega=0.70$ ), but its $95 \%$ CI overlapped zero. Across-site variation in butterfly abundance and richness was not explained by any of the considered environmental factors (Table 2; Appendix A: Table A.3). None of the flower-visitor groups were affected by wildflower strip size.

\section{Associations between flowers and flower-visitors}

In line with the varying responses of the flower-visitor groups to the sown seed mixture treatments, different flower-visitor groups responded differently to the composition of flower species in the flower strip transects (Table 3). Flower cover of sown Fabaceae and Apiaceae species were the most important factors explaining local distribution of bumblebees within the flower strips. Bumblebee abundance was positively related with cover of sown Fabaceae species (model averaged coefficient $\beta=0.27$ ) and negatively to cover of sown Apiaceae species $(\beta=-0.24)$. In contrast, hoverfly abundance was positively correlated with Apiaceae 
Table 2. Model selection and model averaging results for effects of seed mixture and across-site variation in flower strip size, flower variables and proportion semi-natural habitat on abundance of bumblebees, hoverflies and butterflies, and total flower-visitor richness. Candidate models $\left(\Delta \mathrm{AIC}_{\mathrm{c}}<2\right)$ are ranked in order of increasing differences in corrected Akaike Information Criterion. Model averaged parameter estimates $(\beta)$ and $95 \%$ confidence intervals are given for each explanatory variable. Confidence intervals not overlapping zero are indicated in bold. For each model the number of parameters $(k)$, marginal $\mathrm{R}^{2}$ value $\left(\mathrm{R}_{\mathrm{m}}{ }^{2}\right)$ and Akaike model weight ( $)$, which indicates the probability that a model is the best approximating model in the candidate set, is shown. SNH: proportion semi-natural habitat; Flcov: total flower cover; Flrich: total flower richness; Sown flcov: cover of sown flower species; Sown flrich: richness of sown flower species.

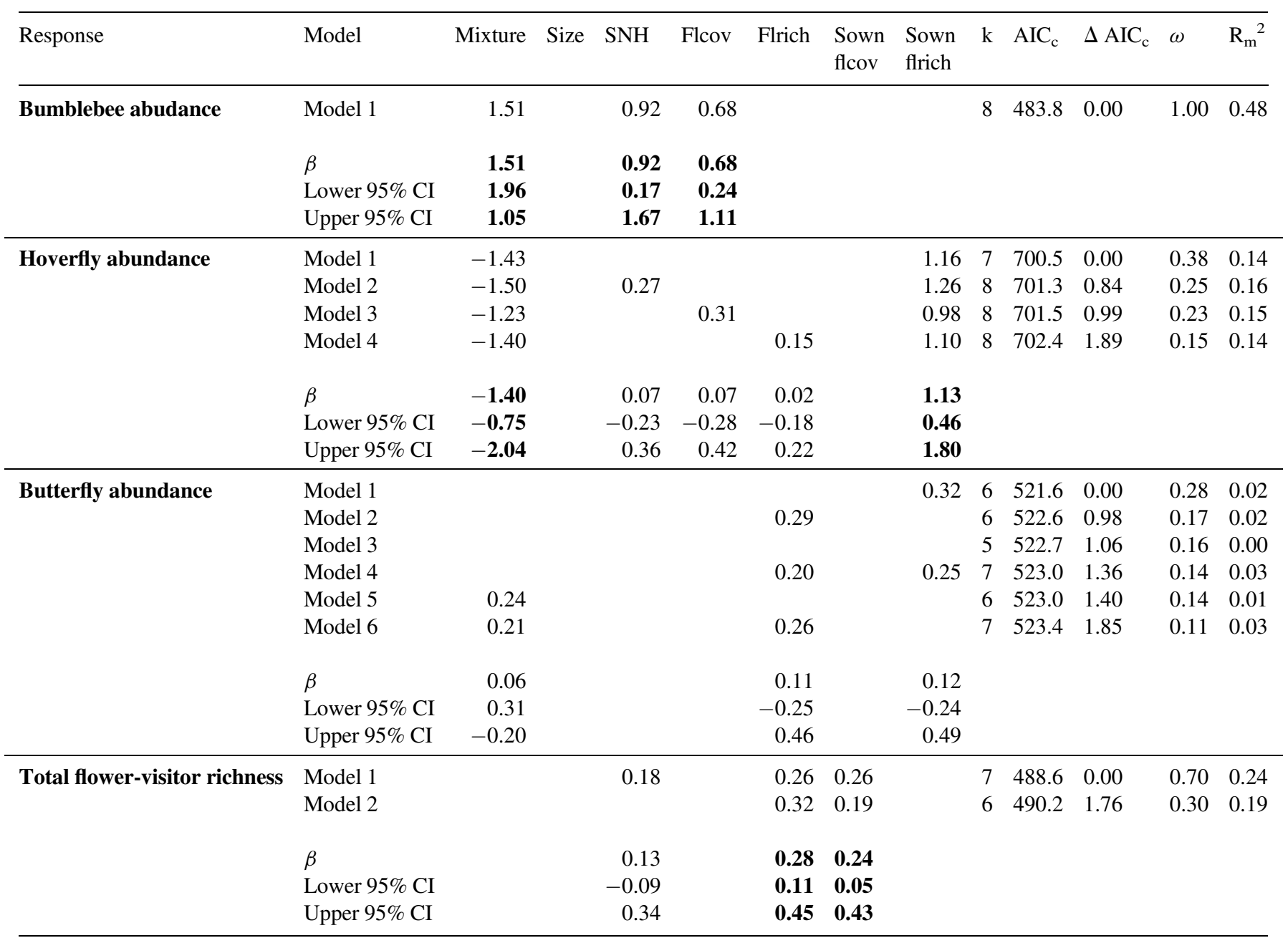

cover $(\beta=0.35)$, and was furthermore positively, but less strongly $(\beta=0.13)$, correlated with total flower richness in the transects. Local butterfly abundance increased across transects with increasing flower richness as well $(\beta=0.28)$, but was negatively correlated with cover of sown Asteroideae $(\beta=-0.17)$. Finally, total flower visitor richness was mainly explained by total flower richness $(\beta=0.17)$, cover of sown Apiaceae $(\beta=0.10)$, and cover of sown Fabaceae ( $\beta=0.09$ ), with total flower visitor-richness being positively correlated with these flower variables.

\section{Discussion}

Developing multi-purpose flower seed mixtures that simultaneously address pollination, pest control and general biodiversity objectives requires insight in the attractiveness of different seed mixtures and their component flower species to different flower-visitor species groups. Using a largescale field experiment under real-world conditions, we showed that bumblebees and hoverflies displayed contrasting responses to the different seed mixtures, with bumblebees clearly and consistently preferring the pollinator mixture and hoverflies the natural enemy mixture. Hoverflies were positively correlated with local cover of Apiaceae, while bumblebees were negatively associated with Apiaceae but positively with Fabaceae. Butterflies, hoverflies and total flower-visitor richness were positively related to local flower species richness, whereas flower richness did not feature in any of the candidate models for bumblebees. Our study suggests that optimising flower mixtures for one species group will not benefit or even comes at the expense of another 

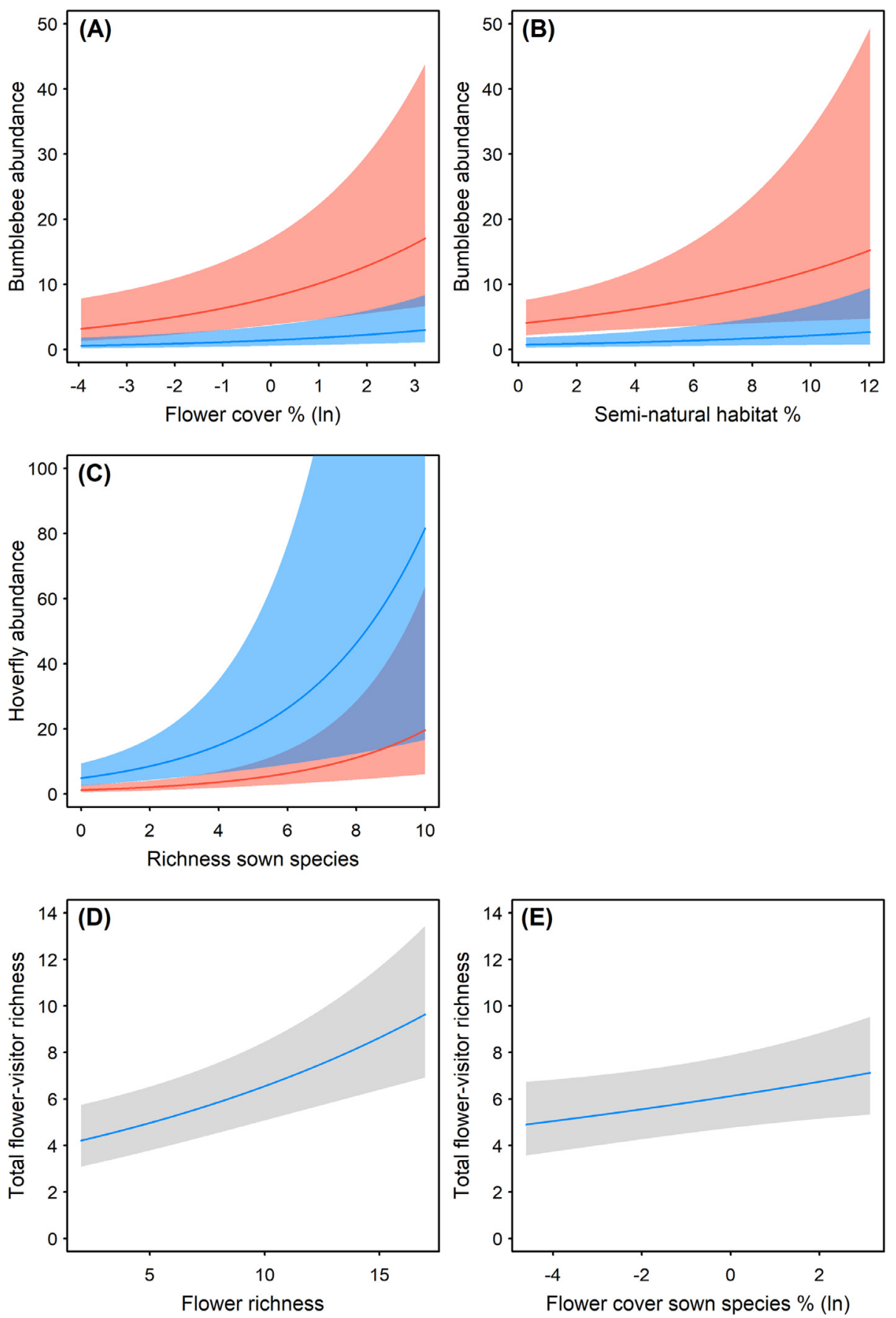

Fig. 2. Conditional partial regression plots for effects of mixture and local and landscape environmental factors on bumblebee abundance (A, B), hoverfly abundance (C) and total flower-visitor richness (D,E) per $250 \mathrm{~m}^{2}$ transect area per survey round. Red: pollinator mixture; blue: natural enemy mixture. Shaded areas indicate $95 \%$ confidence intervals.

species group. Species-rich, multifunctional wildflower strips may therefore benefit several species groups but will maximise neither of them.

As expected, and in line with studies that compared shortand long-corolla mixes at the smaller plot scale (Campbell et al., 2012; Campbell, Wilby, Sutton \& Wäckers, 2017), bumblebees preferred the pollinator mixture (Fig. 2A,B; Appendix A: Fig. A.2A) while hoverflies preferred the natural enemy mixture (Fig. 2C; Appendix A: Fig. A2B). Although we have not directly observed flowerinsect interactions in our study, these patterns appeared to be mainly associated with the presence of Fabaceae species in the pollinator mixture and Apiaceae species in the natural enemy mixture (Table 3), despite their generally relatively low cover (Table 1). Although most bumblebee species are generalists, many species, including the most frequently 
Table 3. Model selection and model averaging results for the associations of flower-visitors with flower taxa in transects within wildflower strips. Candidate models $(\Delta$ AIC $<2)$ are ranked in order of increasing differences in corrected Akaike Information Criterion. Model averaged parameter estimates $(\beta)$ and $95 \%$ confidence intervals are given for each explanatory variable. Confidence intervals not overlapping zero are indicated in bold. For each model the number of parameters $(\mathrm{k})$, marginal $\mathrm{R}^{2}$ value $\left(\mathrm{R}_{\mathrm{m}}{ }^{2}\right)$ and Akaike model weight $(\omega)$ is shown. Flcov: flower cover; Flrich: flower richness; Api: Apiaceae; Ast: Asteroideae; Bor: Borago officinalis; Cen: Centaurea jacea; Cic: Cichorioideae; Fab: Fabaceae; Mal: Malva sylvestris; Pap: Papaver rhoeas.

\begin{tabular}{|c|c|c|c|c|c|c|c|c|c|c|c|c|c|c|c|c|}
\hline Response & Model & Flcov & Flrich & Api & Ast & Bor & Cen & $\mathrm{Cic}$ & $\mathrm{Fab}$ & Mal & Pap & $\mathrm{k}$ & $\mathrm{AIC}_{\mathrm{c}}$ & $\Delta \mathrm{AIC}_{\mathrm{c}}$ & $\omega$ & $\mathrm{R}_{\mathrm{m}}^{2}$ \\
\hline \multirow[t]{7}{*}{ Bumblebee abundance } & Model 1 & & & -0.23 & & & & & 0.26 & 0.15 & 0.16 & 8 & 1270.2 & 0.00 & 0.39 & 0.13 \\
\hline & Model 2 & & & -0.26 & & & & 0.12 & 0.27 & & 0.18 & 8 & 1270.9 & 0.77 & 0.26 & 0.13 \\
\hline & Model 3 & & & -0.24 & & & & 0.13 & 0.27 & 0.17 & & 8 & 1271.5 & 1.30 & 0.20 & 0.12 \\
\hline & Model 4 & & & -0.24 & & & 0.11 & & 0.27 & & 0.19 & 8 & 1272.0 & 1.89 & 0.15 & 0.12 \\
\hline & $\beta$ & & & -0.24 & & & 0.02 & 0.06 & 0.27 & 0.09 & 0.14 & & & & & \\
\hline & Lower $95 \%$ CI & & & -0.45 & & & -0.07 & -0.09 & 0.15 & -0.09 & -0.04 & & & & & \\
\hline & Upper 95\% CI & & & $-\mathbf{0 . 0 3}$ & & & 0.11 & 0.20 & 0.39 & 0.27 & 0.32 & & & & & \\
\hline \multirow[t]{11}{*}{ Hoverfly abundance } & Model 1 & 0.12 & 0.13 & 0.34 & 0.09 & & & & & & & 8 & 2003.0 & 0.00 & 0.19 & 0.11 \\
\hline & Model 2 & 0.16 & 0.12 & 0.35 & & & & & & & & 7 & 2003.1 & 0.11 & 0.18 & 0.10 \\
\hline & Model 3 & 0.16 & 0.14 & 0.33 & & & & & & & -0.08 & 8 & 2003.7 & 0.72 & 0.13 & 0.10 \\
\hline & Model 4 & & 0.11 & 0.39 & 0.13 & & & 0.10 & & & & 8 & 2003.8 & 0.86 & 0.13 & 0.11 \\
\hline & Model 5 & 0.15 & 0.15 & 0.34 & & & & & -0.07 & & & 8 & 2004.1 & 1.08 & 0.11 & 0.10 \\
\hline & Model 6 & 0.14 & 0.10 & 0.36 & & & & 0.06 & & & & 8 & 2004.2 & 1.17 & 0.11 & 0.10 \\
\hline & Model 7 & & 0.13 & 0.38 & 0.13 & & & & & & & 7 & 2004.9 & 1.95 & 0.07 & 0.10 \\
\hline & Model 8 & 0.16 & 0.12 & 0.35 & & 0.04 & & & & & & 8 & 2004.9 & 1.96 & 0.07 & 0.10 \\
\hline & $\beta$ & 0.12 & 0.13 & 0.35 & 0.04 & 0.00 & & 0.02 & -0.01 & & -0.01 & & & & & \\
\hline & Lower $95 \%$ CI & -0.04 & 0.01 & 0.20 & -0.09 & -0.04 & & -0.07 & -0.07 & & -0.09 & & & & & \\
\hline & Upper 95\% CI & 0.27 & 0.24 & 0.49 & 0.17 & 0.05 & & 0.11 & 0.05 & & 0.06 & & & & & \\
\hline \multirow[t]{14}{*}{ Butterfly abundance } & Model 1 & 0.10 & 0.28 & & -0.19 & & & & & & & 7 & 1290.3 & 0.00 & 0.16 & 0.07 \\
\hline & Model 2 & & 0.30 & & -0.16 & & & & & & & 6 & 1290.3 & 0.01 & 0.16 & 0.06 \\
\hline & Model 3 & & 0.28 & & -0.15 & 0.07 & & & & & & 7 & 1291.3 & 0.95 & 0.10 & 0.06 \\
\hline & Model 4 & 0.09 & 0.27 & & -0.19 & 0.07 & & & & & & 8 & 1291.4 & 1.11 & 0.09 & 0.07 \\
\hline & Model 5 & & 0.28 & & -0.15 & & & & & & 0.05 & 7 & 1291.8 & 1.44 & 0.08 & 0.06 \\
\hline & Model 6 & & 0.30 & 0.06 & -0.17 & & & & & & & 7 & 1291.8 & 1.54 & 0.08 & 0.06 \\
\hline & Model 7 & 0.09 & 0.27 & & -0.18 & & & & & & 0.04 & 8 & 1292.0 & 1.66 & 0.07 & 0.07 \\
\hline & Model 8 & 0.10 & 0.26 & & -0.18 & & & & 0.04 & & & 8 & 1292.0 & 1.74 & 0.07 & 0.07 \\
\hline & Model 9 & & 0.27 & & -0.15 & & & & 0.04 & & & 7 & 1292.1 & 1.75 & 0.07 & 0.06 \\
\hline & Model 10 & 0.09 & 0.28 & 0.03 & -0.20 & & & & & & & 8 & 1292.2 & 1.91 & 0.06 & 0.07 \\
\hline & Model 11 & & 0.29 & & -0.16 & & & 0.02 & & & & 7 & 1292.2 & 1.94 & 0.06 & 0.06 \\
\hline & $\beta$ & 0.04 & 0.28 & 0.01 & -0.17 & 0.01 & & 0.00 & 0.01 & & 0.01 & & & & & \\
\hline & Lower $95 \%$ CI & -0.08 & 0.16 & -0.06 & -0.31 & -0.07 & & -0.03 & -0.05 & & -0.05 & & & & & \\
\hline & Upper 95\% CI & 0.17 & 0.40 & 0.07 & $-\mathbf{0 . 0 3}$ & 0.09 & & 0.03 & 0.06 & & 0.07 & & & & & \\
\hline
\end{tabular}


observed B. lapidarius and B. terrestris/lucorum species in the present study, have a clear preference for pollen and/or nectar of Fabaceae plant species (Goulson, Hanley, Darvill, Ellis \& Knight, 2005, 2008; Kleijn \& Raemakers, 2008) whereas Apiaceae are rarely visited by bumblebees, despite their pollen and nectar being accessible to them (Goulson et al., 2008; Wood et al., 2015). The long-corolla Fabaceae species thereby constitute key forage plants whose availability generally benefits bumblebee colony performance and reproduction (Carvell, Bourke, Osborne \& Heard, 2015; Wood et al., 2015), even when the total area of Fabaceae is relatively small (Rundlöf, Persson, Smith \& Bommarco, 2014). Hoverflies, on the other hand, mostly prefer short-corolla flowers with easily accessible nectar (Colley \& Luna, 2000; van Rijn \& Wäckers, 2016). Although hoverflies may visit both short- and long-corolla flower species for pollen (as source of protein), flower choice of the relatively short-tongued hoverflies is predominantly determined by nectar accessibility (Branquart \& Hemptinne, 2000; van Rijn \& Wäckers, 2016). Consequently, hoverfly abundance and richness is generally strongly correlated with the cover of flower species that have easily accessible nectar (van Rijn \& Wäckers, 2016), which explains the observed attractiveness of the natural enemy mixture containing short-corolla flowers, and the observed association with Apiaceae in particular (Cole, Brocklehurst, Robertson, Harrison \& McCracken, 2017; Colley \& Luna, 2000; Wäckers \& Van Rijn, 2012). In addition to Apiaceae, we found that hoverflies were associated with local flower richness within strips as well (Table 3). Although hoverflies have relatively short tongue lengths, there is considerable variation in tongue length amongst hoverfly species, and the range of flower species that individual hoverfly species can exploit varies accordingly as well (Branquart \& Hemptinne, 2000). The positive correlation with local flower richness therefore probably reflects that more diverse flower communities may provide a wider array of accessible flower species to different hoverfly species (Fründ, Linsenmair \& Blüthgen, 2010).

The responses of the target groups used as indicators for wider biodiversity values, i.e. butterflies and total flowervisitor richness, did not differ between mixtures (Table 2). Instead, local butterfly abundance and total flower-visitor richness within strips was best explained by local flower richness (Table 3), further indicating, like the results for hoverflies, that more species-rich plant communities provide foraging niches for a wider variety of flower-visitors (Castagneyrol \& Jactel, 2012; Ebeling, Klein, Schumacher, Weisser \& Tscharntke, 2008; Fründ et al., 2010). For butterflies the association with flower richness, which is generally linked with total plant richness as well (Ebeling et al., 2008; Ekroos et al., 2013), may also reflect greater availability of larval host plants for oviposition (Dainese et al., 2017; Holland, Smith, Storkey, Lutman \& Aebischer, 2015). Local butterfly abundance was furthermore negatively correlated with cover of Asteroideae, of which Achillea millefolium 
made up the large majority (Table 1). Avoidance of this plant species by butterflies has been observed before (Jennersten, 1984; Tudor, Dennis, Greatorex-Davies \& Sparks, 2004) and may be associated with unfavourable floral scent or toxic secondary metabolites to butterfly species, including the - in the present study - most abundant species Pieris rapae (Andersson, 2003; Hasheminia, Sendi, Jahromi \& Moharramipour, 2011). Total flower visitor richness was additionally positively correlated with both cover of Apiaceae and Fabaceae, which reflects the benefit of the presence of Apiaceae in attracting hoverflies and Fabaceae in attracting bumblebees.

We did not find evidence for any interaction effects between wildflower seed mixture and local or landscape environmental variables. This suggests that the current findings on the relative attractiveness of the different seed mixtures to different functional groups of flower-visitors are robust for variation in wildflower strip size, flower composition and surrounding landscape across sites. All flower-visitors except butterflies were affected though by main effects of the considered environmental factors (Table 2; Appendix A: Table A.3). Hoverfly abundance and richness and total flower-visitor richness increased across sites with increasing richness and cover of sown flower species, respectively, thereby stressing the importance of successful establishment and maintenance of the sown flower species in supporting these target groups. On the other hand, total flower-visitor richness was also positively correlated with total richness of sown and unsown species combined, and bumblebees with total flower cover, indicating that spontaneously established flower species in wildflower strips may be important in attracting flower-visitor target groups as well (Warzecha et al., 2018). In turn, variation in richness and cover of sown and total flower species across sites was mainly explained by the original land use of the wildflower strip sites, but with contrasting effects on flower cover and richness. Total and sown flower cover was about two times higher on intensively used arable fields, possibly because these disturbed and more fertile sites provided more suitable conditions to germinate and persist for some species (Kiehl, Kirmer, Donath, Rasran \& Hölzel, 2010), especially for well-performing and dominantly flowering species such as Achillea millefolium (Pywell et al., 2003). In contrast, total flower richness was higher on formerly extensively used fields which may be attributed to lower soil fertility (Ceulemans et al., 2014; Kleijn et al., 2009) or a more diverse seed bank at these sites (Bekker et al., 1997) compared to intensively managed arable land (Storkey, Meyer, Still \& Leuschner, 2012). The proportion of sown species that established in the strips did not differ according to original land use but was consistently higher in the pollinator than in the natural enemy mixture at all sites. This was mainly due to the particularly low establishment of Angelica sylvestris and Anthriscus sylvestris across sites (Table 1), which may have been associated with e.g. seed dormancy or unfavourable local environmental conditions (Kleijn, 2003; Pywell et al., 2003).

Bumblebees were the only flower-visitor group positively correlated with the proportion of semi-natural habitat in the landscape. Bumblebees, being central-place foragers with relatively long colony cycles, benefit from semi-natural habitats as they provide nesting sites (Öckinger \& Smith, 2007) and complementary floral resources throughout the season (Requier, Jowanowitsch, Kallnik \& Steffan-Dewenter, 2020). Bukovinszky et al. (2017) indeed found a positive relationship between $B$. terrestris colony growth rate and cover of semi-natural habitat in this study system in the year prior to the establishment of the wildflower strips. In contrast, non-central-place foraging hoverflies and butterflies, particularly the common species with large flight ranges, are less dependant on semi-natural habitat (Ekroos, Rundlöf \& Smith, 2013; Jauker, Diekoetter, Schwarzbach \& Wolters, 2009). As such, these highly mobile species may aggregate on attractive patches of floral resources from a wider surrounding area and more readily track resource pulses in agricultural landscapes, which also explains the lack of effect of flower strip size on these groups. The absence of effects of wildflower strip size on bumblebees was more surprising, since bumblebee densities have been shown to decrease with increasing wildflower strip size (Carvell et al., 2011, but see Heard et al., 2007). However, in our system, bumblebees may have readily responded to the enhanced floral resource availability by increased production of workers (Bukovinszky et al., 2017), and possibly males and queens (Carvell et al., 2015; Wood et al., 2015). Taken together, the lack of correlation between wildflower strip size and local densities of flower-visitors suggests that, since local densities remained constant, larger wildflower strips proportionally attract higher total abundances of flower-visitors and potentially support larger flower-visitor populations in the surrounding landscape as well, as was shown for wild bees in our study area by Kleijn et al. (2018).

Our results suggest that maximising the different objectives comes with trade-offs between the functional groups that prefer short- (hoverflies) and long-corolla flowers (bumblebees). Diverse, multifunctional wildflower strips may therefore integrate different objectives to a certain extent, but will not optimise any of them. Which plant species to include in a seed mixture then ultimately depends on the priority of the different conservation objectives in a given context. However, our study also shows that establishing flower-rich strips that contain the desired plant species may be easier said than done (Bretzel et al., 2009; Schmidt et al., 2020). In our study we have sown two different mixtures containing eleven and eight flower species, respectively, yet several species were only recorded in a subset of sites and/or their cover was low, especially in the natural enemy mixture. Established cover and richness of sown species was an important determinant of variation in flower-visitor richness and abundance across sites, suggesting that the effect of sown wildflower strips on flower-visiting insects depends not only on the preferences of insects for the specific plant species in the mixture but also on the establishment rate of the plant species that were introduced. Furthermore, although the wildflower strips may nevertheless have been effective from an 
ecological perspective, as shown by Kleijn et al. (2018) who found larger populations of wild bees in our study landscapes with sown wildflower strips compared to control landscapes without wildflower strips, relative low establishment of several of the sown species may have negatively affected farmers' perception of wildflower strip success. Whether sowing wildflower mixtures results in colourful vegetation made up of target species or in swards dominated by grasses and agricultural weeds will therefore significantly affect farmer motivation to adopt this type of biodiversity enhancing management (Van der Meulen, De Snoo \& Wossink, 1996). Selection of flower species for inclusion in seed mixtures should therefore, in addition to considerations with respect to flower strip objectives, explicitly take establishment characteristics of sown plant species into account.

\section{Data accessibility}

All data used in producing this manuscript is freely available through the Dryad Digital Repository: doi:10.5061/dry ad.44j0zpcf4.

\section{Declaration of Competing Interest}

The authors declare that they have no known competing financial interests or personal relationships that could have appeared to influence the work reported in this paper.

\section{Acknowledgements}

We thank all farmers and other land owners for granting access to their land and in particular are grateful to the nature conservation organizations "Natuurmonumenten," "Het Limburgs Landschap," "Staatsbosbeheer," the counties "Groesbeek" and "Horst aan de Maas" and the "Bloeiend Bedrijf" project for funding/facilitating the establishment of the wildflower strips. We also thank Roel de Greeff, Jaco van den Berg and Linda van der Jagt for their assistance during field work.

\section{Funding}

This work was supported by the Netherlands Organization for Scientific Research [NWO-ALW Biodiversity Works Program, Grant No. 841.11.001] and Syngenta.

\section{Supplementary materials}

Supplementary material associated with this article can be found in the online version at doi:10.1016/j. baae.2021.08.014.

\section{References}

Albrecht, M., Kleijn, D., Williams, N. M., Tschumi, M., Blaauw, B. R., Bommarco, R., et al. (2020). The effectiveness of flower strips and hedgerows on pest control, pollination services and crop yield: A quantitative synthesis. Ecology Letters, 23(10), 1488-1498.

Andersson, S. (2003). Foraging responses in the butterflies Inachis io, Aglais urticae (Nymphalidae), and Gonepteryx rhamni (Pieridae) to floral scents. Chemoecology, 13(1), 1-11.

Aviron, S., Herzog, F., Klaus, I., Luka, H., Schupbach, L., \& Jeanneret, P. (2006). Effects of Swiss agri-environmental measures on arthropod biodiversity in arable landscapes. Aspects of Applied Biology, 81, 101.

Balzan, M. V., Bocci, G., \& Moonen, A.-. C. (2014). Augmenting flower trait diversity in wildflower strips to optimise the conservation of arthropod functional groups for multiple agroecosystem services. Journal of Insect Conservation, 18(4), 713-728.

Bartomeus, I., Stavert, J., Ward, D., \& Aguado, O. (2019). Historical collections as a tool for assessing the global pollination crisis. Philosophical Transactions of the Royal Society B, 374, (1763) 20170389.

Bekker, R., Verweij, G., Smith, R., Reine, R., Bakker, J., \& Schneider, S. (1997). Soil seed banks in European grasslands: Does land use affect regeneration perspectives? Journal of Applied Ecology, 1293-1310.

Boetzl, F. A., Krimmer, E., Krauss, J., \& Steffan-Dewenter, I. (2019). Agri-environmental schemes promote ground-dwelling predators in adjacent oilseed rape fields: Diversity, species traits and distance-decay functions. Journal of Applied Ecology, 56(1), 10-20.

Bommarco, R., Kleijn, D., \& Potts, S. G. (2013). Ecological intensification: Harnessing ecosystem services for food security. Trends in Ecology \& Evolution, 28(4), 230-238. doi:10.1016/j. tree.2012.10.012.

Branquart, E., \& Hemptinne, J. L. (2000). Selectivity in the exploitation of floral resources by hoverflies (Diptera: Syrphinae). Ecography, 23(6), 732-742.

Bretzel, F., Pezzarossa, B., Benvenuti, S., Bravi, A., \& Malorgio, F. (2009). Soil influence on the performance of 26 native herbaceous plants suitable for sustainable Mediterranean landscaping. Acta Oecologica, 35(5), 657-663.

Bukovinszky, T., Verheijen, J., Zwerver, S., Klop, E., Biesmeijer, J. C., Wäckers, F. L., et al. (2017). Exploring the relationships between landscape complexity, wild bee species richness and reproduction, and pollination services along a complexity gradient in the Netherlands. Biological Conservation, 214, 312-319.

Burnham, K. P., Anderson, D. R., \& Huyvaert, K. P. (2011). AIC model selection and multimodel inference in behavioral ecology: Some background, observations, and comparisons. Behavioral Ecology and Sociobiology, 65(1), 23-35.

Campbell, A. J., Biesmeijer, J. C., Varma, V., \& Wäckers, F. L. (2012). Realising multiple ecosystem services based on the response of three beneficial insect groups to floral traits and trait diversity. Basic and Applied Ecology, 13(4), 363-370.

Campbell, A. J., Wilby, A., Sutton, P., \& Wäckers, F. (2017). Getting more power from your flowers: Multi-functional flower 
strips enhance pollinators and pest control agents in apple orchards. Insects, 8(3), 101.

Carvell, C., Bourke, A. F., Osborne, J. L., \& Heard, M. S. (2015). Effects of an agri-environment scheme on bumblebee reproduction at local and landscape scales. Basic and Applied Ecology, 16(6), 519-530.

Carvell, C., Osborne, J., Bourke, A., Freeman, S., Pywell, R., \& Heard, M. (2011). Bumble bee species' responses to a targeted conservation measure depend on landscape context and habitat quality. Ecological Applications, 21(5), 1760-1771.

Castagneyrol, B., \& Jactel, H. (2012). Unraveling plant-animal diversity relationships: A meta-regression analysis. Ecology, 93 (9), 2115-2124.

CBS. (2015). Statistics Netherlands - Statline database. Retrieved from http://www.cbs.nl/en-GB/menu/cijfers/statline/

Ceulemans, T., Stevens, C. J., Duchateau, L., Jacquemyn, H., Gowing, D. J. G., Merckx, R., et al. (2014). Soil phosphorus constrains biodiversity across European grasslands. Global Change Biology, 20, 3814-3822.

Chaplin-Kramer, R., de Valpine, P., Mills, N. J., \& Kremen, C. (2013). Detecting pest control services across spatial and temporal scales. Agriculture, Ecosystems \& Environment, 181, 206-212.

Cole, L. J., Brocklehurst, S., Robertson, D., Harrison, W., \& McCracken, D. I. (2017). Exploring the interactions between resource availability and the utilisation of semi-natural habitats by insect pollinators in an intensive agricultural landscape. Agriculture, Ecosystems \& Environment, 246, 157167.

Colley, M., \& Luna, J. (2000). Relative attractiveness of potential beneficial insectary plants to aphidophagous hoverflies (Diptera: Syrphidae). Environmental Entomology, 29(5), 10541059.

Cresswell, C. J., Cunningham, H. M., Wilcox, A., \& Randall, N. P. (2019). A trait-based approach to plant species selection to increase functionality of farmland vegetative strips. Ecology and Evolution, 9(8), 4532-4543.

Dainese, M., Isaac, N. J., Powney, G. D., Bommarco, R., Öckinger, E., Kuussaari, M., et al. (2017). Landscape simplification weakens the association between terrestrial producer and consumer diversity in Europe. Global Change Biology, 23(8), 3040-3051.

Ebeling, A., Klein, A. M., Schumacher, J., Weisser, W. W., \& Tscharntke, T. (2008). How does plant richness affect pollinator richness and temporal stability of flower visits? Oikos (Copenhagen, Denmark), 117(12), 1808-1815.

Ekroos, J., Kuussaari, M., Tiainen, J., Heliölä, J., Seimola, T., \& Helenius, J. (2013a). Correlations in species richness between taxa depend on habitat, scale and landscape context. Ecological Indicators, 34, 528-535.

Ekroos, J., Rundlöf, M., \& Smith, H. G. (2013b). Trait-dependent responses of flower-visiting insects to distance to semi-natural grasslands and landscape heterogeneity. Landscape Ecology, 28(7), 1283-1292.

Feber, R., Smith, H., \& Macdonald, D. (1996). The effects on butterfly abundance of the management of uncropped edges of arable fields. Journal of Applied Ecology, 11911205.

Fründ, J., Linsenmair, K. E., \& Blüthgen, N. (2010). Pollinator diversity and specialization in relation to flower diversity. Oikos (Copenhagen, Denmark), 119(10), 1581-1590.
Goulson, D., Hanley, M. E., Darvill, B., Ellis, J., \& Knight, M. E. (2005). Causes of rarity in bumblebees. Biological Conservation, 122(1), 1-8.

Goulson, D., Lye, G. C., \& Darvill, B. (2008). Diet breadth, coexistence and rarity in bumblebees. Biodiversity and Conservation, 17(13), 3269-3288.

Grass, I., Albrecht, J., Jauker, F., Diekötter, T., Warzecha, D., Wolters, V., et al. (2016). Much more than bees-Wildflower plantings support highly diverse flower-visitor communities from complex to structurally simple agricultural landscapes. Agriculture, Ecosystems \& Environment, 225, 45-53.

Haaland, C., Naisbit, R. E., \& Bersier, L. F. (2011). Sown wildflower strips for insect conservation: A review. Insect Conservation and Diversity, 4(1), 60-80.

Hasheminia, S. M., Sendi, J. J., Jahromi, K. T., \& Moharramipour, S. (2011). The effects of Artemisia annua L. and Achillea millefolium L. crude leaf extracts on the toxicity, development, feeding efficiency and chemical activities of small cabbage Pieris rapae L.(Lepidoptera: Pieridae). Pesticide Biochemistry and Physiology, 99(3), 244-249.

Heard, M., Carvell, C., Carreck, N., Rothery, P., Osborne, J., \& Bourke, A. (2007). Landscape context not patch size determines bumble-bee density on flower mixtures sown for agri-environment schemes. Biology Letters, 3(6), 638-641.

Holland, J. M., Smith, B. M., Storkey, J., Lutman, P. J., \& Aebischer, N. J. (2015). Managing habitats on English farmland for insect pollinator conservation. Biological Conservation, $182,215-222$.

Jauker, F., Diekoetter, T., Schwarzbach, F., \& Wolters, V. (2009). Pollinator dispersal in an agricultural matrix: Opposing responses of wild bees and hoverflies to landscape structure and distance from main habitat. Landscape Ecology, 24(4), 547555.

Jennersten, O. (1984). Flower visitation and pollination efficiency of some North European butterflies. Oecologia, 63(1), 80-89.

Kiehl, K., Kirmer, A., Donath, T. W., Rasran, L., \& Hölzel, N. (2010). Species introduction in restoration project$\mathrm{s}$-Evaluation of different techniques for the establishment of semi-natural grasslands in Central and Northwestern Europe. Basic and Applied Ecology, 11(4), 285-299.

Kleijn, D. (2003). Can establishment characteristics explain the poor colonization success of late successional grassland species on ex-arable land? Restoration Ecology, 11(2), 131-138.

Kleijn, D., Kohler, F., Báldi, A., Batáry, P., Concepcíon, E. D., Clough, Y., et al. (2009). On the relationship between farmland biodiversity and land-use intensity in Europe. Proceedings of the royal society B: Biological sciences, 276, 903-909.

Kleijn, D., Linders, T. E., Stip, A., Biesmeijer, J. C., Wäckers, F. L., \& Bukovinszky, T. (2018). Scaling up effects of measures mitigating pollinator loss from local-to landscapelevel population responses. Methods in Ecology and Evolution, 9(7), 1727-1738.

Kleijn, D., \& Raemakers, I. (2008). A retrospective analysis of pollen host plant use by stable and declining bumble bee species. Ecology, 89(7), 1811-1823.

Kleijn, D., Winfree, R., Bartomeus, I., Carvalheiro, L. G., Henry, M., Isaacs, R., et al. (2015). Delivery of crop pollination services is an insufficient argument for wild pollinator conservation. Nature Communications, 6(1), 1-9.

Korpela, E.-. L., Hyvönen, T., Lindgren, S., \& Kuussaari, M. (2013). Can pollination services, species 
diversity and conservation be simultaneously promoted by sown wildflower strips on farmland? Agriculture, Ecosystems \& Environment, 179, 18-24.

Nielsen, A., Dauber, J., Kunin, W. E., Lamborn, E., Jauker, B., Moora, M., et al. (2012). Pollinator community responses to the spatial population structure of wild plants: A pan-European approach. Basic and Applied Ecology, 13(6), 489-499.

Öckinger, E., \& Smith, H. G. (2007). Semi-natural grasslands as population sources for pollinating insects in agricultural landscapes. Journal of Applied Ecology, 44(1), 50-59.

Ollerton, J., Winfree, R., \& Tarrant, S. (2011). How many flowering plants are pollinated by animals? Oikos (Copenhagen, Denmark), 120(3), 321-326.

Pekas, A., De Craecker, I., Boonen, S., Wäckers, F. L., \& Moerkens, R. (2020). One stone; two birds: Concurrent pest control and pollination services provided by aphidophagous hoverflies. Biological Control 104328.

Powney, G. D., Carvell, C., Edwards, M., Morris, R. K., Roy, H. E., Woodcock, B. A., et al. (2019). Widespread losses of pollinating insects in Britain. Nature Communications, 10 (1), 1-6.

Pywell, R. F., Bullock, J. M., Roy, D. B., Warman, L., Walker, K. J., \& Rothery, P. (2003). Plant traits as predictors of performance in ecological restoration. Journal of Applied Ecology, 40(1), 65-77.

Pywell, R., Warman, E., Hulmes, L., Hulmes, S., Nuttall, P., Sparks, T., et al. (2006). Effectiveness of new agri-environment schemes in providing foraging resources for bumblebees in intensively farmed landscapes. Biological Conservation, 129 (2), 192-206.

R Core Team. (2020). $R$ : A language and environment for statistical computingVienna: Austria: R Foundation for Statistical Computing. Retrieved from https://www.R-project.org/.

Rada, S., Schweiger, O., Harpke, A., Kühn, E., Kuras, T., Settele, J., et al. (2019). Protected areas do not mitigate biodiversity declines: A case study on butterflies. Diversity and Distributions, 25(2), 217-224.

Rader, R., Bartomeus, I., Garibaldi, L. A., Garratt, M. P., Howlett, B. G., Winfree, R., et al. (2016). Non-bee insects are important contributors to global crop pollination. Proceedings of the National Academy of Sciences, 113(1), 146-151.

Requier, F., Jowanowitsch, K. K., Kallnik, K., \& Steffan-Dewenter, I. (2020). Limitation of complementary resources affects colony growth, foraging behavior, and reproduction in bumble bees. Ecology, 101(3), e02946.

Rundlöf, M., Persson, A. S., Smith, H. G., \& Bommarco, R. (2014). Late-season mass-flowering red clover increases bumble bee queen and male densities. Biological Conservation, 172, 138-145.

Scheper, J., Bommarco, R., Holzschuh, A., Potts, S. G., Riedinger, V., Roberts, S. P., et al. (2015). Local and landscape-level floral resources explain effects of wildflower strips on wild bees across four European countries. Journal of Applied Ecology, 52(5), 1165-1175.

Scheper, J., Reemer, M., van Kats, R., Ozinga, W. A., van der Linden, G. T., Schaminée, J. H., et al. (2014). Museum specimens reveal loss of pollen host plants as key factor driving wild bee decline in The Netherlands. Proceedings of the National Academy of Sciences, 111(49), 17552-17557.

Schmidt, A., Kirmer, A., Kiehl, K., \& Tischew, S. (2020). Seed mixture strongly affects species-richness and quality of perennial flower strips on fertile soil. Basic and Applied Ecology, 42, 62-72.

Schmidt, M. H., Lauer, A., Purtauf, T., Thies, C., Schaefer, M., \& Tscharntke, T. (2003). Relative importance of predators and parasitoids for cereal aphid control. Proceedings of the Royal Society of London. Series B: Biological Sciences, 270(1527), 1905-1909.

Stefanescu, C., Peñuelas, J., \& Filella, I. (2005). Butterflies highlight the conservation value of hay meadows highly threatened by land-use changes in a protected Mediterranean area. Biological Conservation, 126(2), 234-246.

Storkey, J., Meyer, S., Still, K. S., \& Leuschner, C. (2012). The impact of agricultural intensification and land-use change on the European arable flora. Proceedings of the royal society B: Biological sciences, 279(1732), 1421-1429.

Symonds, M. R., \& Moussalli, A. (2011). A brief guide to model selection, multimodel inference and model averaging in behavioural ecology using Akaike's information criterion. Behavioral Ecology and Sociobiology, 65(1), 13-21.

Thomas, C., \& Marshall, E. (1999). Arthropod abundance and diversity in differently vegetated margins of arable fields. Agriculture, Ecosystems \& Environment, 72(2), 131-144.

Tschumi, M., Albrecht, M., Collatz, J., Dubsky, V., Entling, M. H., Najar-Rodriguez, A. J., et al. (2016). Tailored flower strips promote natural enemy biodiversity and pest control in potato crops. Journal of Applied Ecology, 53(4), 1169-1176.

Tschumi, M., Albrecht, M., Entling, M. H., \& Jacot, K. (2015). High effectiveness of tailored flower strips in reducing pests and crop plant damage. Proceedings of the royal society B: Biological sciences, 282,(1814) 20151369.

Tudor, O., Dennis, R., Greatorex-Davies, J., \& Sparks, T. (2004). Flower preferences of woodland butterflies in the UK: Nectaring specialists are species of conservation concern. Biological Conservation, 119(3), 397-403.

Van de Pol, M., \& Wright, J. (2009). A simple method for distinguishing within-versus between-subject effects using mixed models. Animal Behaviour, 77(3), 753.

Van der Meulen, H. A. B., De Snoo, G. R., \& Wossink, G. A. A. (1996). Farmers' perception of unsprayed crop edges in the Netherlands. Journal of Environmental Management, 47, 241-255.

Van Rijn, P. C., \& Wäckers, F. L. (2016). Nectar accessibility determines fitness, flower choice and abundance of hoverflies that provide natural pest control. Journal of Applied Ecology, 53(3), 925-933.

Van Strien, A. J., van Swaay, C. A., van Strien-van Liempt, W. T., Poot, M. J., \& WallisDeVries, M. F. (2019). Over a century of data reveal more than $80 \%$ decline in butterflies in the Netherlands. Biological Conservation, 234, 116-122.

Wäckers, F. L., \& Van Rijn, P. C. (2012). Pick and mix: Selecting flowering plants to meet the requirements of target biological control insects. Biodiversity and Insect Pests: Key Issues for Sustainable Management, 9, 139-165.

Warzecha, D., Diekötter, T., Wolters, V., \& Jauker, F. (2018). Attractiveness of wildflower mixtures for wild bees and hoverflies depends on some key plant species. Insect Conservation and Diversity, 11(1), 32-41.

Wood, T. J., Holland, J. M., \& Goulson, D. (2015a). Pollinator-friendly management does not increase the diversity of farmland bees and wasps. Biological Conservation, 187, $120-126$. 
Wood, T. J., Holland, J. M., \& Goulson, D. (2017). Providing foraging resources for solitary bees on farmland: Current schemes for pollinators benefit a limited suite of species. Journal of Applied Ecology, 54(1), 323-333.
Wood, T. J., Holland, J. M., Hughes, W. O., \& Goulson, D. (2015b). Targeted agri-environment schemes significantly improve the population size of common farmland bumblebee species. Molecular Ecology, 24(8), 1668-1680.

Available online at www.sciencedirect.com ScienceDirect 